\title{
Characteristics of High-Power Diode-Laser Welds for Industrial Assembly
}

\author{
C.A. Walsh", H.K.D.H. Bhadeshia*, A. $\mathrm{Lau}^{+}$, B. Matthias ${ }^{+}$, R. Oesterlein ${ }^{+}$, and J. Drechsel ${ }^{\circ}$, \\ ${ }^{*}$ Dept. Materials Science, University of Cambridge, UK; ${ }^{+}$ABB Corp. Research, Ladenburg, \\ Germany; ${ }^{\circ}$ Laserinstitut Mittelsachsen e.V., Mittweida, Germany.
}

Recent progress in available beam power and beam quality has meant that high power diode lasers (HPDL) may soon become prime tools for welding in many assembly applications in industrial production. Their compact size and low weight makes them particularly suitable for use in conjunction with robotic control. The advantages of laser welding over conventional welding techniques include more reproducible welds, smaller heat affected zones and lower distortion at high welding speeds. The implementation of diode laser systems will require an understanding of the effect of operating parameters on weld performance. This paper reports on the characteristics of diode-laser spot and seam welds in low carbon steel sheets. The size, shape, hardness, strength and microstructure of the welds have been measured and analysed as a function of parameters such as laser power, welding time and welding speed.

\section{$\underline{\text { Introduction }}$}

Diode lasers have been around for some time, but their low power and poor beam quality has restricted their use to applications such as pumping solid state lasers, soldering small components, welding plastics, brazing and surface treatments (hardening and cladding). ${ }^{1,2,3}$ The technology has now advanced to such an extent that it is possible to produce laser beams of sufficiently high power density to induce the melting and welding of sheet metal. Schubert et ll $^{4}$ demonstrated this using a $1.4 \mathrm{~kW}$ HPDL with a beam intensity of $1.1 \times 10^{4} \mathrm{~W} / \mathrm{cm}^{2}$. As this intensity is much lower than that of conventional laser sources (typically $10^{6} \mathrm{~W} / \mathrm{cm}^{2}$ ), the system at the time was capable only of conduction mode welding. Apart from demonstrating its use as a local heat source for the hardening of cast iron and the formation of coating layers ${ }^{5}$, it was possible to join sheets of aluminium and steel. ${ }^{6,7,8}$ The laser beam melted the aluminium, so that it acted like a solder, and created a joint between the sheets at speeds of up to $0.85 \mathrm{~m} / \mathrm{min}$. Conduction mode welding was carried out on very thin metal sheets and at slow welding speeds: $0.8 \mathrm{~mm}$ thick sheet steel at $1 \mathrm{~m} / \mathrm{min} ; 2 \mathrm{~mm} \mathrm{Al}$ alloy sheet at $0.35 \mathrm{~m} / \mathrm{min} ; 3 \mathrm{~mm} \mathrm{Mg}$ sheet at 0.4 $\mathrm{m} / \mathrm{min}^{6}$

A $2 \mathrm{~kW}$ HPDL system has been developed by Jenoptik ${ }^{9,} 10$ which has a beam diameter of 0.96 $\mathrm{mm}$ and intensity of $2.35 \times 10^{5} \mathrm{~W} / \mathrm{cm}^{2}$. This system is capable of carrying out 'keyhole mode' welding and has successfully produced welds in $\mathrm{Al}$, Ti and steel. ${ }^{9}$ Abe et $a l^{10}$ used this diode 
laser system to investigate the effect of shielding gas flow rate and nozzle angle (with workpiece) on welding speed and penetration. They found that the penetration depth tended to increase slightly with increasing nozzle angle and was also sensitive to the gas flow rate. An optimum flow rate existed at which the penetration depth was maximised $(2.3 \mathrm{~mm}$ with a $2 \mathrm{~kW}$ beam and a welding speed of $1 \mathrm{~m} / \mathrm{min}$ ). They were able to produce a full penetration butt weld in a $5 \mathrm{~mm}$ thick stainless steel plate at $0.24 \mathrm{~m} / \mathrm{min}$, which had a parallel sided bead shape and no defects, and carried out high speed welding of $1 \mathrm{~mm}$ thick mild steel plate at $4 \mathrm{~m} / \mathrm{min}$.

Rofin Sinar HPDL systems have beam intensities of up to $3.2 \times 10^{5} \mathrm{~W} / \mathrm{cm}^{2}$ and $2.5 \mathrm{~kW}$ powers. With this, Gillner et al. ${ }^{3}$ produced deep penetration welds in $3 \mathrm{~mm}$ and $6 \mathrm{~mm}$ steel sheet. $\mathrm{Ng}$ and Watson $^{11}$ used a $1.5 \mathrm{~kW}$ Rofin laser to compare the properties of butt welds in $1.5 \mathrm{~mm}$ thick, high carbon steel plate with those produced with a $1 \mathrm{~kW} \mathrm{CO}$ laser. The beam intensity of the HPDL system was only $2.1 \times 10^{4} \mathrm{~W} / \mathrm{cm}^{2}$ whilst that of the $\mathrm{CO}_{2}$ laser was $1.3 \times 10^{5} \mathrm{~W} / \mathrm{cm}^{2}$. Nevertheless, the size of the welds was similar in both cases, which they attributed to better optical coupling between the material and the diode laser light. The weld properties were investigated over a range of welding speeds from 0.48 to $0.66 \mathrm{~m} / \mathrm{min}$. The hardness increased and weld width decreased with welding speed. At speeds less than $0.6 \mathrm{~m} / \mathrm{min}$ the diode laser welds had smaller widths and higher hardness values than the $\mathrm{CO}_{2}$ laser weld, which is indicative of a higher cooling rate. The tensile strength of the $\mathrm{CO}_{2}$ laser welds increased slightly with speed, whilst the strength of the diode laser weld was only slightly lower below $0.6 \mathrm{~m} / \mathrm{min}$ and decreased further with welding speed to about half that of the $\mathrm{CO}_{2}$ laser weld at $0.66 \mathrm{~m} / \mathrm{min}$. The poor strength of the diode laser welds at speeds above $0.6 \mathrm{~m} / \mathrm{min}$ was attributed to centre-line cracks in the fusion zone.

All this work indicates that HPDL systems could become viable alternatives to resistance welding prevalent in a variety of industries. With this in mind, it was our aim to characterise the weld size, shape, imperfections, strength, hardness and microstructure, as a function of the laser operating parameters, of lap welds in low-carbon steel sheets. Both spot welds and short seam welds (stitch welds) have been investigated with a view to defining an optimum parameter space and to generate experimental data for an on-going project on the mathematical modelling of such welds. In this paper we use the weld fusion zone volume to estimate the energy transfer efficiency for seam welds and report on the hardness and strength measurements. Full details of the weld shape as a function of operating parameters will be published elsewhere.

\section{$\underline{\text { Experimental details }}$}

A $2.2 \mathrm{~kW}$ JOLD 1000 diode laser was used in these experiments. The laser beam, of diameter $1 \mathrm{~mm}$, was focused onto the top surface of the workpiece at normal incidence with a $50 \mathrm{~mm}$ focal length lens. A series of laser spot welds were produced in $2 \mathrm{~mm}$ thick sheets of D52X low carbon steel using beam powers of 1.0, 1.4 and $2.23 \mathrm{~kW}$ and welding times of $0.15-2.65 \mathrm{~s}$. (Note that these are not strictly welds since the spots were made in single sheets of steel.) Argon shielding gas was used in all cases. Lap joints were made by placing a stitch weld (short seam weld) at the centre of a $20 \mathrm{~mm}$ overlap of two steel sheets. The sheets were $40 \mathrm{~mm}$ by $110 \mathrm{~mm}$ rectangles, $0.77 \mathrm{~mm}$ thick and made of DC04 low carbon steel. Lap welds were produced both with and without the use of an Ar shielding gas, in order to study its effect. A range of different 
welding speeds $(10-50 \mathrm{~mm} / \mathrm{s})$ and stitch lengths $(5-20 \mathrm{~mm})$ were investigated for laser powers of 1.4 and $2.26 \mathrm{~kW}$. The chemical compositions of both materials are given in Table 1. A Struers Accutom-5 machine was used to cut a vertical section through the spot welds and a transverse cross-section about half way along the length of the stitch welds. The sections were polished and etched in $2 \%$ nital and observed using two different microscopes. Low magnification 'dark field' images of the weld were obtained using a Heerbrugg Wild microscope. Higher magnification bright field images of the microstructure were obtained using a Leitz Laborlux $12 \mathrm{ME} \mathrm{S}$ optical microscope. The images were digitised and analysed using image processing software, enabling the weld dimensions and fusion zone volume or cross-sectional area to be measured. The hardness of the spot welds was measured using a Vickers Pyramid hardness tester and loads of 1 to $10 \mathrm{~kg}$. The hardness of the seam welds were measured using a Mitutoyo MVK-H2 hardness testing machine with a $200 \mathrm{~g}$ load. In general three measurement were made from the centre of the weld fusion zone; the mean value is reported in this paper. The tensile strength of the weld joints was measured and the peak load before yield recorded.

\begin{tabular}{|c|c|c|c|c|c|c|c|c|}
\hline Material & $\begin{array}{c}\mathbf{C} \\
(\mathbf{w t} \%)\end{array}$ & $\begin{array}{c}\mathbf{S i} \\
(\mathbf{w t} \%)\end{array}$ & $\begin{array}{c}\mathbf{M n} \\
(\mathbf{w t} \%)\end{array}$ & $\begin{array}{c}\mathbf{C r} \\
(\mathbf{w t} \%)\end{array}$ & $\begin{array}{c}\text { Mo } \\
(\mathbf{w t} \%)\end{array}$ & $\begin{array}{c}\mathbf{N i} \\
(\mathbf{w t} \%)\end{array}$ & $\begin{array}{c}\mathbf{V} \\
(\mathbf{w t} \%)\end{array}$ & $\begin{array}{c}\mathbf{N} \\
(\mathbf{p p m} \text { by wt) }\end{array}$ \\
\hline D52X & 0.07 & 0.10 & 0.92 & 0.04 & $<0.01$ & 0.03 & $<0.01$ & 50 \\
\hline DC04 & 0.03 & 0.09 & 0.22 & 0.03 & $<0.01$ & 0.02 & $<0.01$ & 20 \\
\hline
\end{tabular}

Table 1: Chemical composition of the base metals.

\section{Weld shape}

Typical examples of the spot and stitch welds are shown in figure 1. In general the welds were free of pores or cracks, apart from an occasional small pore, as indicated in the figure. Some cratering of the top surface was evident in the spot welds, indicative of material loss. The stitch welds, however, had a crater, involving material loss, only at one end of the weld. The welds produced without shielding gas tended to be more parallel sided, but had a smaller width and fusion zone volume. The gas plasma causes scattering of the laser beam but increases the fraction of incident laser power absorbed by the workpiece (see figure 2).
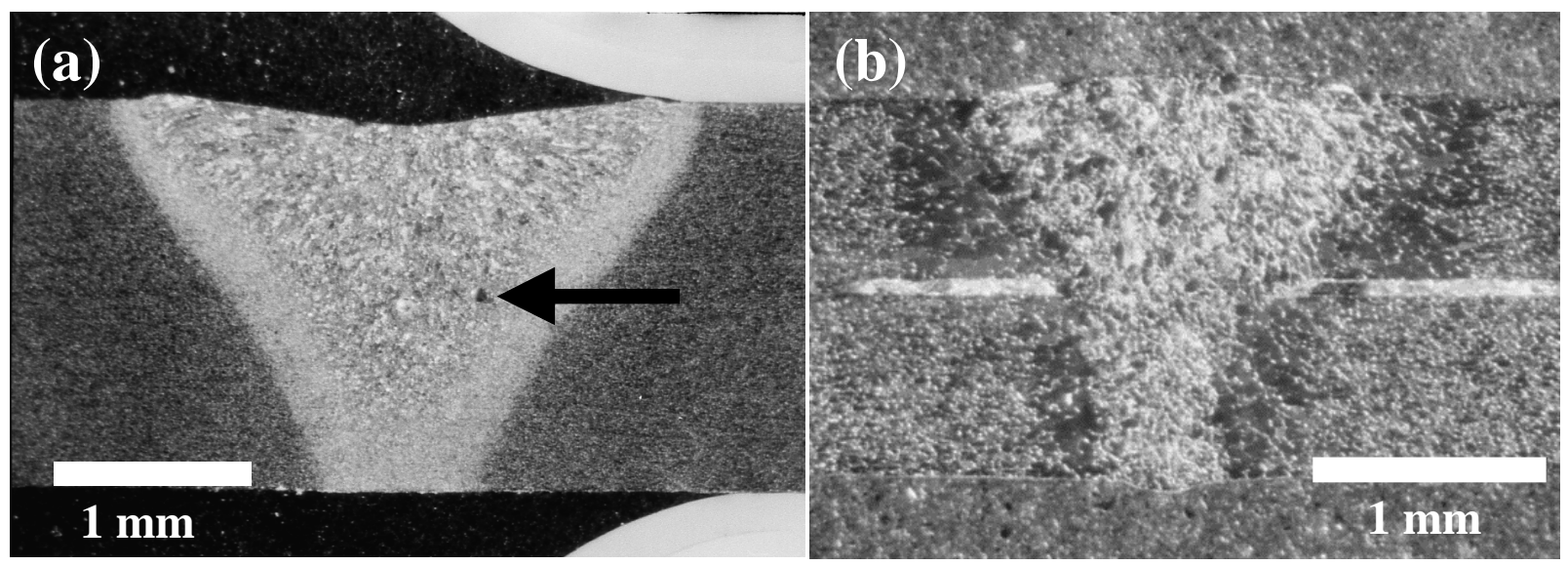

Figure 1

(a) 'Dark field' image of a spot weld produced with a $2.23 \mathrm{~kW}$ beam for $0.18 \mathrm{~s}$. The arrow indicates the position of a small pore in the fusion zone. (b) Transverse cross-section through a $10 \mathrm{~mm}$ stitch weld produced using a $2.26 \mathrm{~kW}$ beam and a welding speed of $35 \mathrm{~mm} / \mathrm{s}$. 


\section{Energy transfer efficiency and melting efficiency}

Two important parameters in all models of welding are the fraction of incident energy in the laser beam that is actually absorbed by the material and the amount subsequently used to melt the metal. The energy transfer efficiency $\eta$ is defined as the ratio of the heat absorbed by the workpiece and the laser output power. The melting efficiency $\eta_{\mathrm{m}}$ is defined as the ratio of the energy used for melting the metal and the heat input. For seam welds the melting efficiency is given by Fuerschbach ${ }^{12}$ as $\eta_{m}=v A \delta h / \eta_{o}$, where $v$ is the welding speed, $q_{o}$ is the laser output power, $A$ is the cross-sectional area of the weld fusion zone and $\delta h$ is the enthalpy of melting. A similar equation can be written for spot welds: $\eta_{m}=V \delta h / \eta q_{o} t$, where $V$ is the volume of the fusion zone and $t$ the welding time. Although the transfer efficiency is not known, the product $\eta \eta_{\mathrm{m}}$ could be calculated from the fusion zone volume or area for each weld. These values are given in figure 2 for the various laser operating powers. The value of $10.4 \mathrm{~J} / \mathrm{mm}^{3}$ given for 1018 low-carbon steel in reference 12 for $\delta h$ is used here. In general, a higher proportion of energy is used to melt the metal at higher laser powers; this is partly caused by changes in the energy transfer efficiency, which is known to increase with laser power. ${ }^{12}$ Fuerschbach also measured the energy transfer efficiency of laser welds in several different materials and produced a material-independent model for the efficiency in terms of two dimensionless parameters. The equation is given here in the form:

$$
\chi=\eta \Gamma\left[0.48-0.29 \exp \left(\frac{-\eta \Gamma}{6.8}\right)-0.17 \exp \left(\frac{-\eta \Gamma}{59}\right)\right]
$$

where $\chi=v^{2} A / \alpha^{2}, \Gamma=q_{o} v / \alpha^{2} \delta h$ and $\alpha$ is the thermal diffusivity at the liquidus temperature (taken to be $5.5 \mathrm{~mm}^{2} / \mathrm{s}$, as for 1018 steel). The only unknown quantity in this equation is the energy transfer efficiency, which could therefore be estimated by fitting the equation to the data for stitch welds. However, as the transfer efficiency is dependent on the laser power and shielding gas, a fit was made for each laser power used $(1.4 \mathrm{~kW}$ and $2.26 \mathrm{~kW})$. The resulting values for the transfer efficiency are given in table 2 . It should be noted that the difference

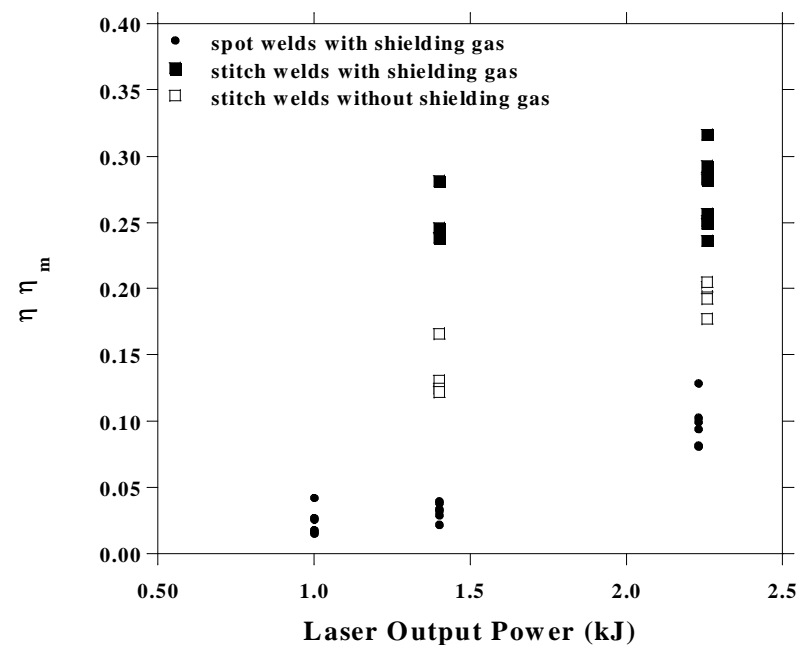

Figure 2

Comparison of the energy transfer and melting efficiencies for spot and stitch welds.

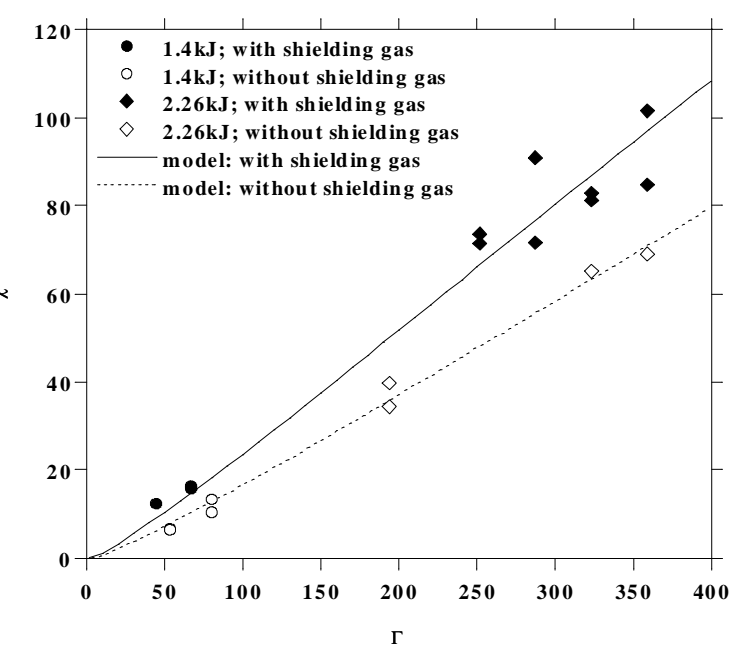

Figure 3

Comparison of experimental values of $\chi$ and $\Gamma$ with the model after fitting it to the data points to obtain values for the energy transfer efficiency. 
between the values for the different laser powers is not significant due to the low number of data points. However, there is a significant difference between the energy transfer efficiencies obtained from welds produced with and without the use of a shielding gas. As expected from the smaller fusion zone volume of the welds produced without a shielding gas, the energy transfer efficiency is significantly lower when no shielding gas is used. A fit was also made to all the data points, irrespective of laser power used, to obtain mean values for the transfer efficiency with and without the use of shielding gas. These values are also given in table 2 . They are almost identical to the values for a laser power of $2.26 \mathrm{~kW}$. The fit of equation 1 using these values are compared with the experimental data in figure 3; a satisfactory fit to the lower power data points is also obtained.

\begin{tabular}{|c|c|c|}
\hline Laser Power $(\mathrm{kW})$ & Efficiency - with shielding gas & Efficiency - without shielding gas \\
\hline 1.4 & 0.64 & 0.38 \\
\hline 2.26 & 0.57 & 0.43 \\
\hline 1.4 and 2.26 & 0.57 & 0.42 \\
\hline
\end{tabular}

Table 2: Energy transfer efficiencies for the diode laser stitch welds.

\section{$\underline{\text { Hardness }}$}

Another important parameter in all welding processes is the amount of energy put into a unit length of weld. Given the energy transfer efficiency, this quantity can be calculated from the incident laser power. The energy has to be dissipated as the weld cools; it therefore has a major effect on the cooling rate over the temperature range in which solid-state phase transformations occur in the steel. As a general principle, a smaller heat input leads to a larger cooling rate and harder microstructures. ${ }^{13}$
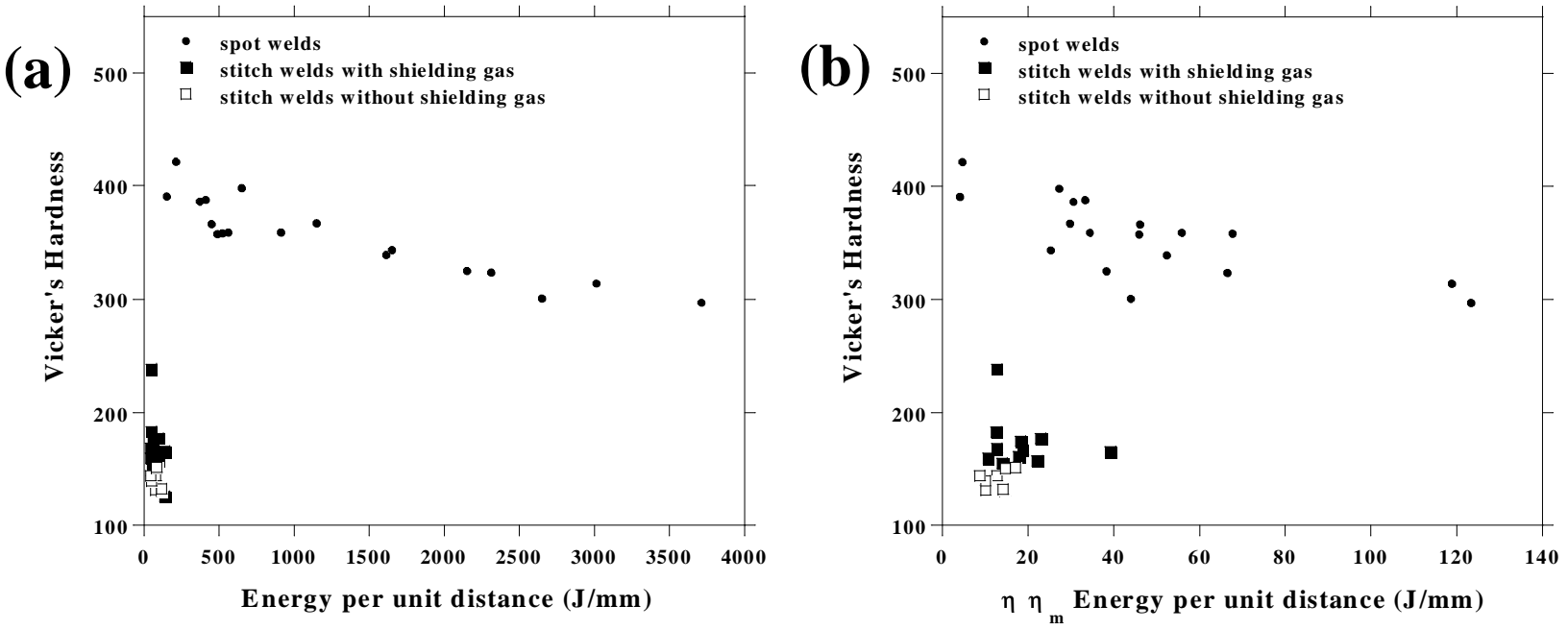

Figure 4

Hardness of the spot and stitch welds as a function of (a) incident laser energy per unit distance and (b) energy used for melting the fusion zone per unit distance.

The hardness of a weld is an important quality control parameter and there are often upper limits prescribed, usually on the basis of experience in service. Figure 4(a) shows that the 
hardness correlates strongly with energy input per unit dimension. In the case of the spot weld, the latter refers to the spot diameter whereas in the stitch weld the dimension is a unit length of stitch. In both cases, the hardness increases as the incident energy per unit length decreases and hence the cooling rate increases. Figure 4(b) compares the hardness dependence on the energy used for melting the fusion zone in the spot and stitch welds ( $V \delta h$ or $v A \delta h$ respectively). For any given energy, the lowest hardness values, and presumably cooling rates, are obtained in stitch welds produced without the use of a shielding gas, whilst the highest hardness and cooling rates occur in the spot welds. A possible explanation for lower cooling rates in the welds without shielding gas, is that the Ar gas flow may be enhancing the cooling rate by removing heat from the surface of the workpiece. There are two reasons for the higher cooling rates in the spot welds. The first is that the geometry of a spot weld allows a more rapid dissipation of heat, which can flow in all radial directions. In the case of a stitch weld, however, the heat flows primarily normal to the welding direction. For a given heat input, the cooling rate is therefore expected to be faster for the spot weld, leading to harder microstructures. Figure 5 compares the microstructures of the fusion zone in a spot weld and a stitch weld. The energy used for melting the fusion zone was similar in both cases ( 38.3 and $39.4 \mathrm{~J} / \mathrm{mm}$ ), however the microstructure of the stitch weld shows a mixture of allotriomorphic and Widmanstätten ferrite, whereas that of the spot welds also contains bainite and martensite, which is indicative of a faster cooling rate in the spot welds.

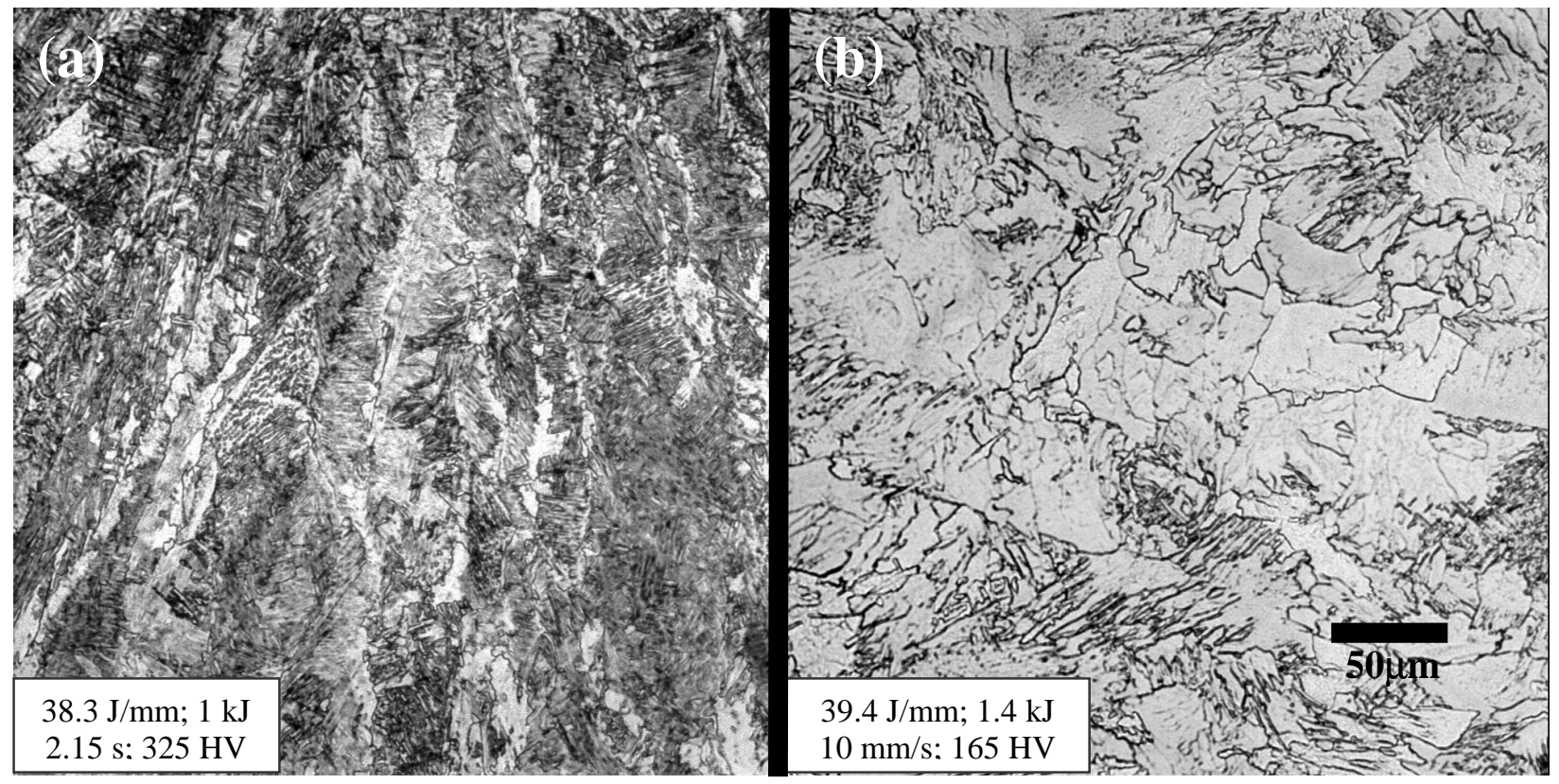

Figure 5

Micrographs of the weld fusion zone in (a) a spot weld and (b) a stitch weld. The values of the energy used to melt the fusion zone per unit distance, the laser power, the welding time or welding speed and the hardness of the fusion zone metal are given in each case.

A further reason for the greater hardness of the spot welds results from the significantly larger manganese and carbon concentrations of the steel D52X when compared with steel DC04. Figure 6 shows the time-temperature-transformation diagrams for the two alloys, calculated using the method described in reference 14. In each case, the upper ' $\mathrm{C}$ ' curve represents the onset of reconstructive transformations such as allotriomorphic ferrite and pearlite, whereas the lower ' $\mathrm{C}$ ' 
curve is for the onset of displacive transformations such as Widmanstätten ferrite and bainite. The horizontal line at the lowest temperature represents the onset of martensitic transformation. It is apparent from these curves that softer microstructures (forming at higher temperatures) are expected in steel DC04. It is particularly pertinent to note that the carbon concentration of DC04 is close to its solubility in ferrite. All of the high temperature transformations which involve the diffusion of carbon can become extremely rapid in such circumstances. ${ }^{15}$ These results clearly indicate that the steel chemical composition must be taken into account in assessing the new welding processes. It may even be necessary to undertake a sensitivity analysis to cover the range of chemical compositions that fall within the specification of the component manufacturer.

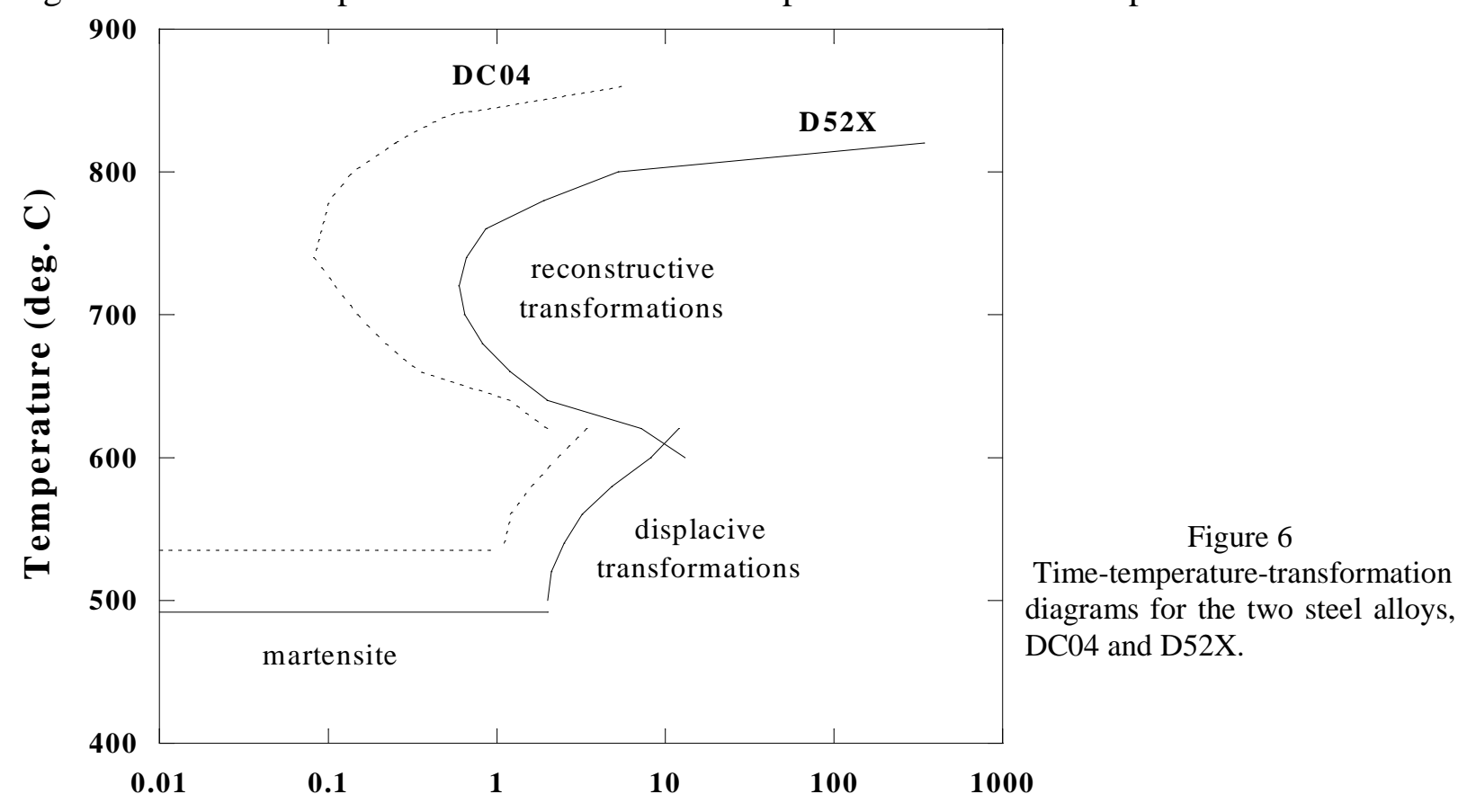

Time (s)
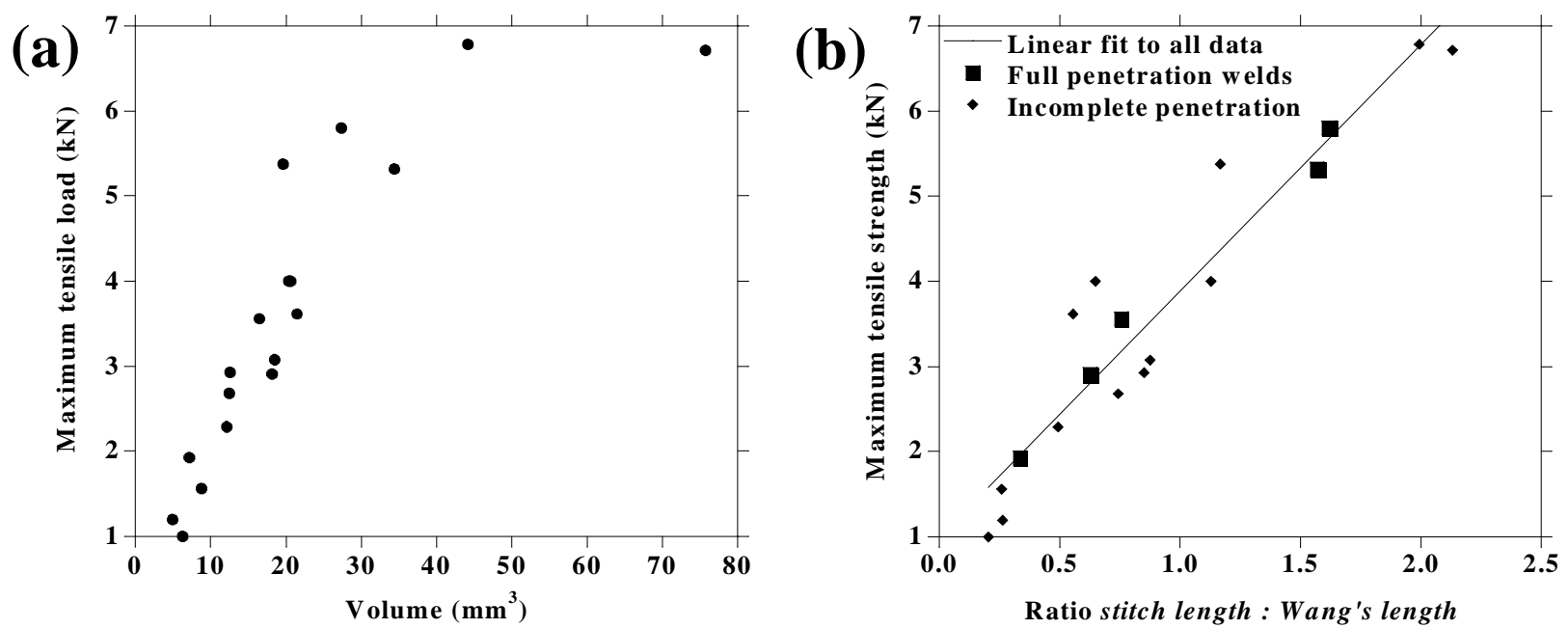

Figure 7

Maximum tensile load of the diode laser lap joints plotted against (a) the volume of the weld fusion zone and (b) the ratio of the actual stitch length and the Wang length (see text). 


\section{Weld Strength}

Shear tensile testing was carried out on a number of lap joints similar to those analysed above. The maximum load before shear varied from 1.0 to $6.8 \mathrm{kN}$. The most important determining factor appears to be the volume of the fusion zone. Figure 7(a) shows that, apart from one weld, the shear strength is directly proportional to the fusion zone volume (stitch length $\times$ crosssectional area). In order to help assess the viability of using these welds as a replacement for resistance spot welds, it is useful to compare these tensile shear strength values with the required minimum weld strength value of a resistance spot weld in metal sheets of similar thickness. Table D.1 of the British Standard BS $1140^{16}$ tabulates typical minimum weld strength values for resistance spot welds in low carbon steel of $280 \mathrm{~N} / \mathrm{mm}^{2}$ minimum tensile strength. The laser welds were carried out in $0.77 \mathrm{~mm}$ thick sheet steel of type DC04 with a tensile strength about 270 to $350 \mathrm{~N} / \mathrm{mm}^{2}$. For a sheet thickness of $0.8 \mathrm{~mm}$, the required resistance spot nugget size ( $5 \sqrt{\text { sheet thickness }}$ ) would be $4.5 \mathrm{~mm}$ with a minimum weld strength of $3.6 \mathrm{kN}$. Many of the welds fail to achieve this value. However, a potentially more useful way of assessing the maximum tensile strength of these laser welds, is to use the results of an earlier work by Wang ${ }^{17}$ on $\mathrm{CO}_{2}$ laser welds. This work tabulated the required dimensions of resistance spot welds and laser welds of equivalent strength for a range of sheet metal gages. For a spot weld of diameter $4.66 \mathrm{~mm}$ in sheet metal of thickness $0.8 \mathrm{~mm}$ the required laser weld dimensions are given in table 3. A second order polynomial can be fitted to these values:

$$
\text { Bead length } / \mathrm{mm}=38.428-37.134 \times(\text { width } / \mathrm{mm})+11.857 \times(\text { width } / \mathrm{mm})^{2}
$$

This equation was used to evaluate Wang's recommended bead length for each laser lap weld. The width of the fusion zone at the interface between the metal sheets (faying surfaces) was used to calculate the required bead length. All these values, along with the welding parameters, are given in table 4 . In some welds the width of the fusion zone changed abruptly at the faying surfaces. In such cases the smaller value for the weld width was used. It should be noted that the width of many laser welds lie outside the range of values given by Wang (0.8-1.2 mm). The use of the equation 2 in these cases may be inaccurate. However, a plot of the measured tensile strength against the ratio of the actual bead length to Wang's recommended length, given in figure 7(b), show a reasonable correlation for all data points. The best set of data (full penetration welds, with widths of between 0.8 and $1.2 \mathrm{~mm}$ ) are shown as solid black squares. The remaining data points correspond to welds with partial penetration or with widths which lie outside the range of values given by Wang. An important result from this graph is the value of $3.9 \mathrm{kN}$ for the tensile strength when the weld length is equal to Wang's recommended value. This is greater than the minimum required value of $3.6 \mathrm{kN}$ for a resistance spot weld. ${ }^{16}$

\begin{tabular}{|l|c|c|c|c|c|}
\hline Bead Width $(\mathrm{mm})$ & 0.8 & 0.9 & 1.0 & 1.1 & 1.2 \\
\hline Bead Length $(\mathrm{mm})$ & 16.33 & 14.56 & 13.18 & 11.94 & 10.93 \\
\hline
\end{tabular}

Table 3: Required laser weld dimensions given by $\mathrm{Wang}^{17}$.

\section{$\underline{\text { Summary and conclusions }}$}

A high power diode laser system was used to make lap joints in low carbon steel sheet by forming a short stitch weld. With suitable choice of parameters defect-free, full-penetration 
welds can be produced which have similar tensile strengths to resistance spot welds. The energy transfer efficiency of the process was calculated using known models, giving values of 0.57 and 0.42 for welding with and without the use of an Ar shielding gas respectively. The former value agrees well with measured efficiencies of the $\mathrm{CO}_{2}$ laser seam welding process, ${ }^{12}$ which suggests that once a keyhole has been formed, the coupling between the laser light and the material is independent of wavelength. The energy transfer efficiency for spot welds could not be evaluated, but it was evident that a significantly lower proportion of the incident laser energy was used to produce the weld melt pool. This resulted in higher cooling rates and the formation of harder microstructural phases than in the stitch welds. In both stitch and spot welds, an increase in heat input per unit distance resulted in lower cooling rates and lower hardness values. The hardness was also shown to be very sensitive to the chemical composition of the steel. Future models for calculating the microstructure and hardness of the weld fusion zone will need to take into account both the chemical composition and the cooling rate. The tensile strength of the welds was found to be approximately proportional to the volume of the weld fusion zone. It was shown, however, that the most relevant dimensions were the weld length and the weld width at the faying surfaces; the calculations carried out by Wang for $\mathrm{CO}_{2}$ laser welds proved a sound model for correlating these dimensions with the weld strength.

\begin{tabular}{|c|c|c|c|c|c|c|}
\hline $\begin{array}{c}\text { Laser } \\
\text { Power }(\mathbf{k W})\end{array}$ & $\begin{array}{c}\text { Welding } \\
\text { Speed (mm/s) }\end{array}$ & $\begin{array}{c}\text { Stitch } \\
\text { Length } \\
\mathbf{( m m})\end{array}$ & $\begin{array}{c}\text { Width at } \\
\text { Faying } \\
\text { Surfaces (mm) }\end{array}$ & $\begin{array}{c}\text { Cross- } \\
\text { sectional } \\
\text { Area } \mathbf{( m m}^{\mathbf{2}} \mathbf{)}\end{array}$ & $\begin{array}{c}\text { Maximum } \\
\text { Tensile Load } \\
\mathbf{( N )}\end{array}$ & $\begin{array}{c}\text { Wang's } \\
\text { Recommnded } \\
\text { Length (mm) }\end{array}$ \\
\hline 1.4 & 15 & 10 & $2.23-0.71$ & 2.14 & 3616 & 17.96 \\
\hline 1.4 & 18 & 10 & 0.98 & 1.24 & 2688 & 13.45 \\
\hline 1.4 & 15 & 20 & 1.32 & 2.21 & 6784 & 10.04 \\
\hline 1.4 & 18 & 20 & $0.95-0.76$ & 0.98 & 5376 & 17.13 \\
\hline 1.4 & 10 & 20 & $3.22-1.61$ & 3.78 & 6720 & 9.38 \\
\hline 1.4 & 12 & 20 & $1.08-1.06$ & 1.37 & 5805 & 12.37 \\
\hline 2.26 & 45 & 5 & $0.52-0.44$ & 1.24 & 1002 & 24.28 \\
\hline 2.26 & 45 & 5 & $0.84-0.67$ & 0.97 & 1202 & 18.83 \\
\hline 2.26 & 45 & 10 & 0.61 & 1.21 & 2292 & 20.28 \\
\hline 2.26 & 50 & 15 & $0.85-0.76$ & 1.23 & 3080 & 17.13 \\
\hline 2.26 & 50 & 15 & 0.73 & 0.84 & 2926 & 17.60 \\
\hline 2.26 & 50 & 20 & 0.73 & 1.03 & 4003 & 17.72 \\
\hline 2.26 & 35 & 5 & 0.65 & 1.76 & 1565 & 19.21 \\
\hline 2.26 & 27 & 5 & 0.88 & 1.42 & 1928 & 14.90 \\
\hline 2.26 & 35 & 10 & $0.96-0.82$ & 1.82 & 2912 & 15.92 \\
\hline 2.26 & 27 & 10 & $1.01-1.00$ & 1.65 & 3555 & 13.21 \\
\hline 2.26 & 40 & 15 & 0.49 & 1.36 & 4000 & 23.03 \\
\hline 2.26 & 40 & 20 & $1.16-1.03$ & 1.72 & 5320 & 12.73 \\
\hline
\end{tabular}

Table 4

Laser lap weld parameters, weld fusion zone dimensions and maximum tensile load of the joint. When two values for the width are given, they relate to the width at the upper and lower faying surface.

\section{$\underline{\text { References }}$}

1. H.K. Tönshoff, A. Berndt, M. Stürmer, D. Golla and J. Schumacher. Diode Lasers for Material Processing. Journal de Physique IV. C4, Spl. JP 111, Vol. 4: April, 1994; pp. 59-63. 
2. T. Holt. Stacks of Energy - High Power Laser Diode Arrays. Welding and Metal Fabrication. Vol. 66: Jan-Feb, 1998; pp. 21-22.

3. A. Gillner, P. Loosen, D. Petring, K. Wissenbach and R. Poprawe. Industrial Applications of High Power Diode Lasers. Proc. ICALEO '99. San Diego, California: 1999.

4. E. Schubert, M. Grupp, and G. Sepold. Materialbearbeitung mit Hochleistungsdioden-lasern (Teil 1). Laser Magazin. Vol. 2: 1998; pp. 14-17.

5. E. Schubert, T. Seefeld, and G. Sepold. Materialbearbeitung mit Hochleistungsdioden-lasern (Teil 2). Laser Magazin. Vol. 3: 1998; pp. 12-14.

6. E. Schubert, M. Klassen, I. Zerner and G. Sepold. Materialbearbeitung mit Hochleistungsdiodenlasern (Teil 3). Laser Magazin. Vol. 4: 1998; pp. 17-20.

7. Anon. Diode Lasers Join Aluminium to Steel. Industrial Laser Solutions. Vol. 14: May, 1999; pp. 23-28.

8. E. Schubert and I. Zerner. Lasergestütztes Fügen von Werkstoffkombinationen. Blech Rohre Profile. Vol. 4, 1999; pp. 76-81.

9. F. Dorsch, F.X. Daiminger, P. Hennig and V, Blümel. $2 \mathrm{~kW}$ cw Fiber-coupled Diode Laser System. SPIE Proceedings AHPLA 99. Vol. 3889. Osaka 1999.

10. N. Abe, R. Higashino, M. Tsukamoto, S. Noguchi and S. Miyake. Materials Processing Characteristics of a $2 \mathrm{~kW}$ Class High Power Density Direct Diode Laser System. Trans. JWRI. Vol. 28: No. 2, 1999; pp. 9-13.

11. E. S. Ng and I. A. Watson. Characteristics of $\mathrm{CO}_{2}$ and Diode Laser Welding of High Carbon Steels. Journal of Laser Applications. Vol. 11, 1999; pp. 273-278.

12. P.W. Fuerschbach. Measurement and Prediction of Energy Transfer Efficiency in Laser beam Welding. Welding Journal. Vol. 75: January, 1996; 24-s - 34-s.

13. H.K.D.H. Bhadeshia, L.-E. Svensson and B. Gretoft. A Model for the Development of Microstructure in Low-Alloy Steel (Fe-Mn-Si-C) Weld Deposits. Acta Metallurgica. Vol. 33, 1985; pp. 1271-1283.

14. H.K.D.H. Bhadeshia. A Thermodynamic Analysis of Isothermal Transformation Diagrams. Metal Science. Vol. 16, 1982; pp. 159-165.

15. H.K.D.H. Bhadeshia and L.-E. Svensson. Mathematical Modelling of Weld Phenomena. Ed. H. Cerjak and K. E. Easterling. Cambridge: University Press (IOM), 1993; pp. 109-182.

16. British Standard BS 1140: 1993. Specification for Resistance Spot Welding of Uncoated and Coated Low Carbon Steel.

17. P.-C. Wang. Calculation of Laser Beam Weld Specification for Automotive Sheet Steel. Welding Journal. Vol. 72: No. 4, 1993; pp. 155-s - 163-s.

Harry Bhadeshia (Professor of Physical Metallurgy) and Carrie Walsh (research physicist) are from the Phase Transformations and Complex Properties Group of the Materials Science Department at Cambridge University, UK. Andrew Lau (research scientist in the Mechatronics Division), Roland Hans Oesterlein (Senior Scientist for Manufacturing Automation) and Björn Matthias (Head of the Mechatronics Group) are from ABB Corporate Research in Ladenburg, Germany. Jan Drechsel is with the Laser Institute in Mittelsachsen as Project Group Leader in the development of High Power Diode Lasers for Material Processing. 